\title{
The role of tropical deep convective clouds on temperature, water vapor, and dehydration in the tropical tropopause layer (TTL)
}

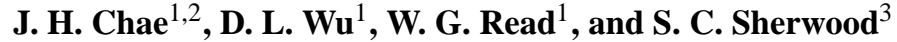 \\ ${ }^{1}$ Jet propulsion Laboratory, California Institute of Technology, Pasadena, California, USA \\ ${ }^{2}$ Joint Institute for Regional Earth System Science and Engineering University of California, Los Angeles, California, USA \\ ${ }^{3}$ Climate Change Research Centre, University of New South Wales, Sydney, Australia
}

Received: 23 March 2010 - Published in Atmos. Chem. Phys. Discuss.: 7 April 2010

Revised: 1 April 2011 - Accepted: 17 April 2011 - Published: 27 April 2011

\begin{abstract}
Temperature and water vapor variations due to clouds in the tropical tropopause layer (TTL) are investigated using co-located MLS, CALIPSO, and CloudSat data. Convective cooling occurs only up to the cloud tops, with warming above these heights in the TTL. Water vapor and ozone anomalies above the cloud tops are consistent with the warming being due to downward motion. Thicker clouds are associated with larger anomalies. Environmental water vapor below cloud tops can be either higher or lower than when clouds are absent, depending on the cloud top height. The critical factor determining the sign of this change appears to be the relative humidity. In general cloud-forming processes hydrate the environment below $16 \mathrm{~km}$, where the air after mixing between cloud and the environmental air does not reach saturation, but clouds dehydrate above $16 \mathrm{~km}$, as the larger temperature drop and the high initial relative humidity cause supersaturation to occur. Negative water vapor anomalies above cloud tops compared to clear skies suggest another dehydration mechanism operating above the detected cloud layers.
\end{abstract}

\section{Introduction}

The tropical tropopause is important for understanding the future state of our climate system because tropospheric air, which includes water vapor and other trace gases, enters the stratosphere preferentially through this layer (Brewer, 1949). The tropical tropopause is not a fixed material surface

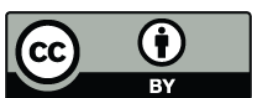

Correspondence to: J. H. Chae (junghyo.chae@aya.yale.edu) but rather a mixed layer, with both tropospheric and stratospheric characteristics; it is termed the tropical tropopause layer (TTL, Fueglistaler et al., 2009). The bottom of the TTL, located near $15 \mathrm{~km}$, is usually defined as the level of zero net radiative heating where the net radiative heating changes from cooling to heating. Radiatively, the air above this level tends to rise, owing to the wave-driving stratospheric Brewer-Dobson circulation, and it eventually enters the stratosphere, whereas the air below this level sinks due to convective circulations. The top of the TTL, located at a height of $\sim 18 \mathrm{~km}$, is the maximum height of overshooting convection (sometimes it can reach up to $20 \mathrm{~km}$ ). Therefore, the bottom of the TTL is the lowest level where stratospheric features can be found, whereas the top of the TTL is the highest level where tropospheric features are apparent.

One of most important unsolved questions is the water vapor transport process from the troposphere to the stratosphere, especially because the analysis of recent decadal records shows that water vapor in the stratosphere is increasing. Water vapor is a greenhouse gas, and long-lived stratospheric water vapor can affect the global energy budget, and it has been shown that increasing water vapor in the stratosphere cools the stratosphere but heats the troposphere (Forster and Shine, 1999; Smith et al., 2001). It is commonly agreed that transport and dehydration processes occur within the TTL, but there is no concrete hypothesis on the manner in which water vapor is transported from the troposphere to the stratosphere (e.g., Read et al., 2008). Two hypotheses have been considered. "Cold trap dehydration" is the hypothesis that assumes a slow ascent by large-scale freeze-drying through a particularly low temperature area over the western Pacific. Lagrangian trajectory studies (Fueglistaler et al. 2005) and the frequent existence of in-situ thin cirrus clouds

Published by Copernicus Publications on behalf of the European Geosciences Union. 
Table 1. Offset temperature obtained by comparison with GPS data at each MLS pressure level.

\begin{tabular}{cccccccccccc}
\hline Pressure $(\mathrm{hPa})$ & 46 & 56 & 68 & 83 & 100 & 121 & 147 & 178 & 215 & 261 & 316 \\
\hline Off-set $T(\mathrm{~K})$ & 0.24 & 1.06 & 1.73 & 1.21 & -0.99 & -1.37 & -0.24 & 0.99 & 1.96 & 1.30 & 0.54 \\
\hline
\end{tabular}

near the TTL (Jensen et al. 1996) support this hypothesis. The other hypothesis is based on "convective dehydration," which occurs mainly due to the effects of deep overshooting convection (Sherwood and Dessler, 2001).

However, neither of these hypotheses fully explains the process of water vapor entry into the tropical stratosphere. Some modeling studies show that overshooting convection, penetrating the cold point, hydrates the lower stratosphere instead of dehydrating it because these overshooting clouds can contain cloud ice, which can sublimate under the warmer temperatures (Jensen et al., 2007; Corti et al., 2008). On the other hand, it is observed that HDO, the heavy water isotope, changes very little with height in the TTL. This cannot be explained by the slow ascent dehydration process (Kuang et al., 2003; Dessler et al., 2007; Read et al., 2008).

It has long been recognized that the upper troposphere in the western Pacific is the coldest longitudinally (Arakawa, 1950). This upper tropospheric cold region has links to tropical deep convection because the western Pacific is a frequent deep convection area. However, the mechanism of TTL cooling, in relation to tropical deep convection, has been debated and there are several hypotheses centered on the following: convective detrainment and diabatic turbulent mixing with the environment (Sherwood 2000; Sherwood et al., 2003; Kuang and Bretherton, 2004), convectively generated waves (Tsuda et al., 1994; Zhou and Holton, 2002; Randel and $\mathrm{Wu}, 2005)$, radiative cooling by reduction in longwave heating (Webster and Stephens, 1980; Norton, 2001), and intrinsic responses to convective heating in the free troposphere, which is followed by divergence, ascent and adiabatic cooling (Holloway and Neelin, 2007).

Even though temperature and water vapor in the TTL are closely linked to tropical convective activity, the manner in which clouds influence these variables is still uncertain because there are few datasets that contain collocated cloud and environmental thermodynamical information. Additionally, previous cloud top height measurements using the brightness temperature technique had low biases (Sherwood et al., 2004), and therefore might have missed some important features. In this study, we use high-resolution satellite data to identify the convective influence on temperature and water vapor.

We focus especially on cloud top height in order to investigate how cloud ice influences environmental temperature and water vapor variations. We hypothesize that cloud top height is one of the most important factors that influences environmental temperature and water vapor in the TTL, because the thermodynamic condition of cloudy air uplifted into the TTL is much different from that of the environment.

The data and methods used in this study are described in the next section. Section 3 deals with cloud top heights obtained from CALIPSO and CloudSat, and how these values differ from previous satellite data. Section 4 shows the relationships between cloud top heights and environmental temperature, water vapor, and ozone. Conclusions and a discussion are presented in Sect. 5.

\section{Data}

We use MLS v2.2 temperature, water vapor, and ozone datasets, which have been validated by Schwartz et al. (2008), Read et al. (2007), and Froidevaux et al. (2008). MLS temperatures have been modified by offset factors (Table 1) obtained by comparison with GPS data at each pressure level to remove the MLS temperature bias, which is about $\sim 1.5 \mathrm{~K}$ in the TTL (Schwartz et al., 2008). MLS data have a vertical resolution of $3 \sim 4 \mathrm{~km}$, and a horizontal resolution of approximately $7 \mathrm{~km}$ across track and $200 \sim 300 \mathrm{~km}$ along track. We re-calculate MLS relative humidity using modified temperature data, and relative humidity in this paper is with respect to ice because we are interested in the TTL.

Level 1 CALIPSO backscattering data are used for cloud information. We use only the nighttime dataset because of excessive noise during the day (see Wu et al., 2011). Cloud top height is the most important variable in our analysis, and CALIPSO is the best source of this information. CloudSat is used to determine thick and thin clouds because CALISPO backscattering is quickly attenuated in clouds.

Aura, CALIPSO, and CloudSat are different satellites, and there are only limited time periods when CALIPSO measurements are close to MLS within the MLS horizontal resolution, though all these are in the A-train (Stephens et al., 2002) in the same orbit and pass a given latitude within a short time period $(7 \mathrm{~min})$. We use data over a nine-month period from May 2008 to January 2009, when the orbits of MLS and CALIPSO are within $10 \mathrm{~km}$ of each other at the equator. Only nighttime tropical data $\left(15^{\circ} \mathrm{S}\right.$ to $\left.15^{\circ} \mathrm{N}\right)$ are used because we are mainly interested in the TTL.

We attempt to divide clouds into three categories: thick, thin and multi-layered, because these cloud types have different radiative heating effects. Thin clouds correspond to isolated thin cirrus clouds which cannot be detected by CloudSat, with thicknesses less than $3 \mathrm{~km}$, and whose maximum 

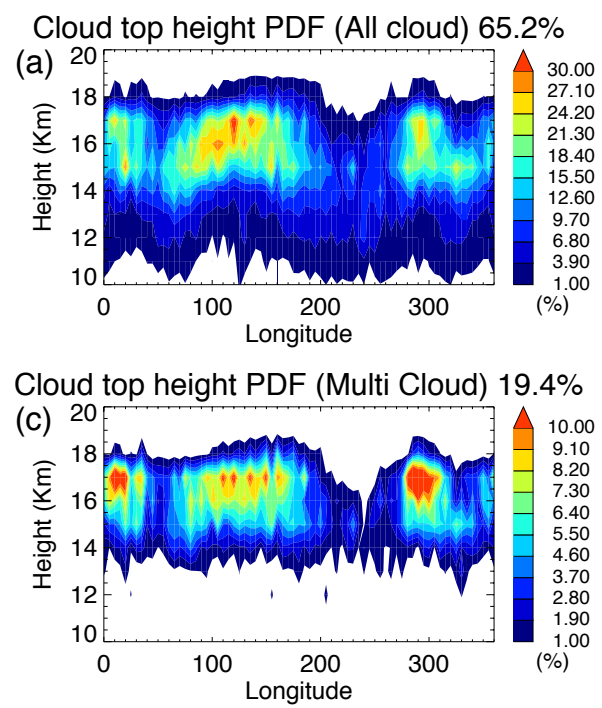
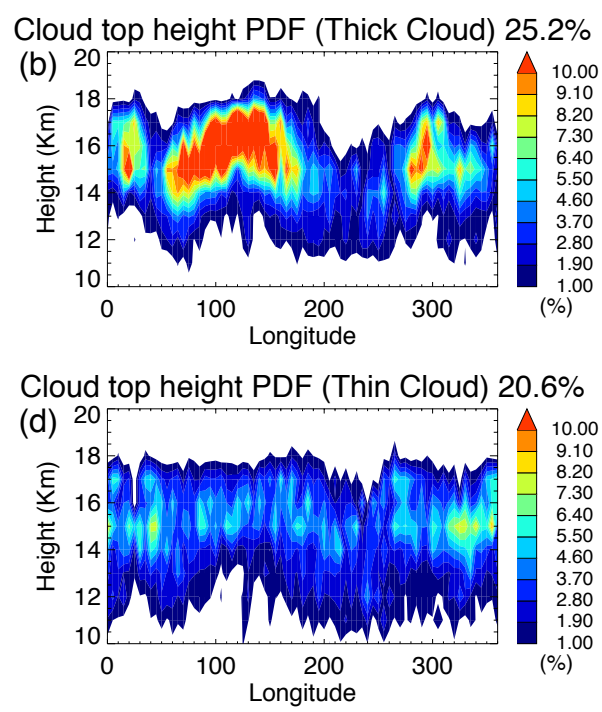

Fig. 1. Cloud top height frequency of $15^{\circ} \mathrm{S}-15^{\circ} \mathrm{N}$ with longitude for all clouds (a), thick clouds (deep convection) (b), multi-layered clouds (c), and isolated thin clouds (thin cirrus clouds) (d).

backscatter is less than $0.0005 \mathrm{~km}^{-1} \mathrm{sr}^{-1}$ from the CALIPSO data. Note that thin cirrus clouds in this paper are not divided into convectively generated and in-situ cirrus clouds. Thick clouds are defined to be at least $3 \mathrm{~km}$ thick vertically, with CloudSat ice water content (IWC) greater than $2 \mathrm{mg} / \mathrm{m}^{3}$ in the overlapping region. We categorize clouds as multilayered clouds if there are other clouds present, with top heights greater than $10 \mathrm{~km}$, beneath thin cirrus clouds.

\section{Distribution of cloud tops}

Figure 1 shows the zonal distribution of cloud top height frequency averaged over the period from May 2008 to January 2009. In Fig. 1a, we see a prominent cloud top height mode between 14 and $17 \mathrm{~km}$, and three longitudinal areas (Africa, western Pacific, and Central America) contain frequent thick convective clouds (Fig. 1b). Multi-layered cloud frequency is similar to thick cloud frequency because the upper thin cirrus clouds above lower high-topped clouds are associated with deep convective clouds (Fig. 1c). On the other hand, isolated thin cirrus clouds (either convectively generated or in-situ cirrus) in Fig. 1d show little longitudinal dependence. Our analysis indicates that half of the cirrus clouds have underlying deep convection or are associated with other thin clouds $(19.4 \%)$, and the other half are isolated single layer cirrus clouds $(20.6 \%)$. This analysis is consistent with the result of a previous study (McFarquhar et al., 2000).

We note that lidar observations from CALIPSO are very sensitive to optically thin clouds, and the cloud top heights inferred from these observations are much higher than other observations. Several previous studies have shown that CALIPSO cloud top heights are about $3 \mathrm{~km}$ higher than
MODIS or AIRS heights in tropical deep convective clouds (Weisz et al., 2007; Holz et al., 2008; Wu et al., 2009).

\section{Results}

\subsection{Cloud top height vs. temperature}

Figure 2 shows the time mean zonal and vertical temperature anomaly structure (deviations from the zonal mean) within $15^{\circ} \mathrm{S}-15^{\circ} \mathrm{N}$ obtained by removing the annual cycle at each altitude. Warm anomalies occur up to $13 \mathrm{~km}$, followed by colder temperatures near the TTL over the western Pacific where strong deep convection frequently occurs. In the eastern Pacific, in the descending region of the Walker circulation, warm anomalies are observed above cold anomalies in the troposphere. These zonal temperature anomalies are consistent with the findings of previous studies (Randel et al., 2003; Randel and Wu, 2005; Gettelman and Birner, 2007; Fueglistaler et al., 2009). These zonal temperature anomalies are also sustained in clear skies because of the difference between the radiative relaxation time and cloud lifetime scales (Fig. 2b). The temperature anomalies induced by clouds can remain in a clear sky due to the relatively long radiative relaxation time, though it depends on the perturbation wavelength. The radiative relaxation time scale in the TTL is approximately $30 \sim 120$ days (Hartmann et al., 2001), which is longer than cloud lifetimes (typically $1 \sim 2$ days).

To see the effect of an individual cloud on the local environmental temperature, we investigate temperature anomalies from local $\left(5^{\circ}\right.$ by $5^{\circ}$ latitude-longitude bins) clear sky mean temperatures rather than from the zonal mean. When there are no clear skies (e.g. Western Pacific area), we use 

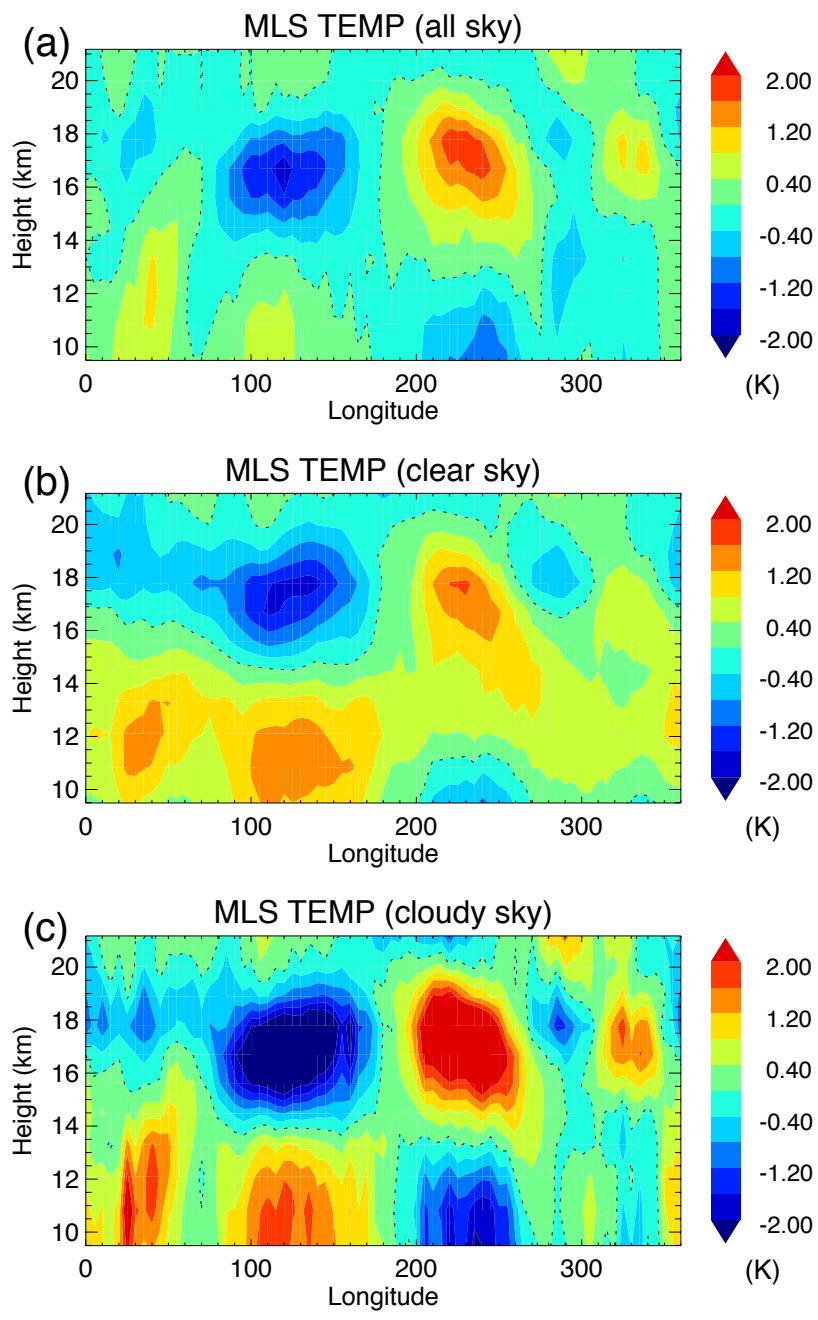

Fig. 2. Time mean zonal and vertical temperature anomalies from the zonal mean with removal of the annual cycle at each altitude $\left(15^{\circ} \mathrm{S}-15^{\circ} \mathrm{N}\right)$.

the average value of the nearest clear sky mean temperature. Figure 3a shows the average temperature anomalies for conditions in which there are clouds with tops higher than $10 \mathrm{~km}$. Note that Fig. 3a is considerably different from Fig. 2c because of the different background temperature. Figure $2 \mathrm{c}$ shows temperature anomalies from cloudy sky zonal mean temperatures, but Fig. 3a shows temperature anomalies from local clear sky temperatures. Therefore, Fig. 3a is similar to the subtraction of Fig. $2 b$ from $c$. The right panels show the zonal average of each cloud thickness with height. Any local space in Fig. 3a can include both conditions, i.e., above cloud top at times and below at other times $(14 \sim 18 \mathrm{~km}$ following Fig. $3 b$ and c). Nevertheless, Fig. 3a shows that there are cold anomalies below $16 \mathrm{~km}$, the level which is usually below cloud tops, with warm anomalies above the cold anomalies, mostly above the cloud tops. There is little longitudinal variation, except that the temperature anomaly tilts eastward
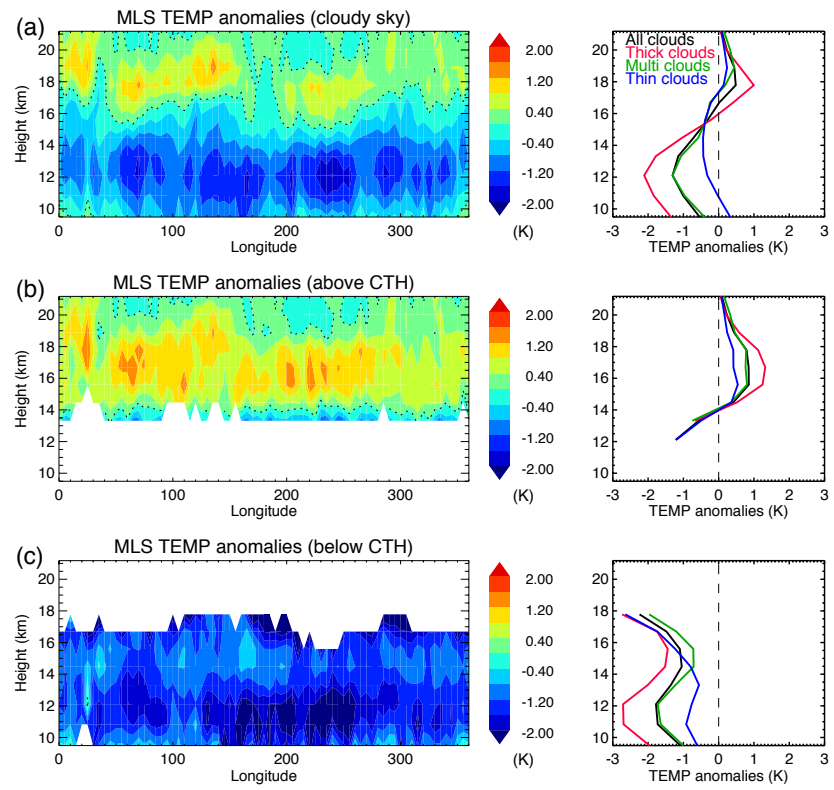

Fig. 3. Time mean vertical profiles of temperature anomaly from the local, clear-sky mean temperature for cloud tops above $10 \mathrm{~km}$ (a). (b) the same as (a) except that only data at least $1.5 \mathrm{~km}$ higher than the cloud top height $(\mathrm{CTH})$ are included in the average. (c) the same as (a) except data height is below cloud top but not by more than $3 \mathrm{~km}$. Right figures show zonally averaged anomalies of absolute value.

with height over two longitudinal bands. One is from the Indian Ocean to the west Pacific, and the other is from the eastern Pacific to Central America. This eastward tilt with height agrees well with the maximum cloud top occurrence (see Fig. 1; see also Randel et al., 2003).

Figures $3 \mathrm{~b}$ and $\mathrm{c}$ show in detail how clouds correlate with the environmental temperature above and below cloud tops. Temperature data only from locations at least $1.5 \mathrm{~km}$ above cloud tops are used in Fig. $3 \mathrm{~b}$ since the MLS vertical resolution is about $3 \mathrm{~km}$, so we can be confident of eliminating cloud contamination if the MLS reference height is at least $1.5 \mathrm{~km}$ higher than the average CALIPSO cloud top height. To reduce retrieval errors below cloud top, we use reference levels, that are below cloud tops but not lower than $3 \mathrm{~km}$ from cloud top (Fig. 3c). These two figures show that the temperature anomalies have opposite signs above and below the cloud top with warm anomalies above the cloud and cold anomalies below the cloud top level in the TTL.

Figure 4 is similar to Fig. 3 in which temperature anomalies are the subtraction of clear from cloudy skies with only clouds with tops $>10 \mathrm{~km}$ considered, and Fig. 4 shows the temperature anomalies at the height relative to cloud top. Therefore, the y-axis indicates the distance from cloud tops (plus sign is above and minus sign is below cloud tops), and positive anomalies indicate warmer temperature for cloudy skies. This calculation further clarifies that a warm anomaly 


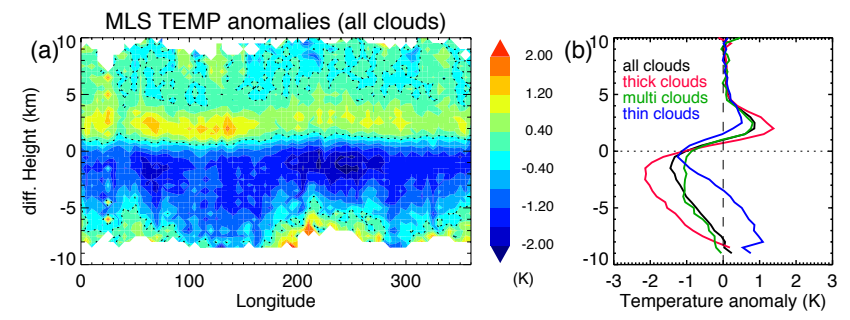

Fig. 4. As in Fig. 3a except temperature anomalies are averaged according to their position relative to cloud top height.

occurs above the cloud top and a cold anomaly below it, and little longitudinal variation exists, though there are very small cold anomalies far above the cloud top in some areas (Fig. 4a). There is longitudinal variation far below the cloud top: cooling anomalies are deeper over frequent deep convective areas and warm anomalies are apparent below cold anomalies, especially over weaker convective regions (e.g., the eastern Pacific).

Figure $4 \mathrm{~b}$ shows zonal averages segregated according to cloud thickness. The magnitudes of the anomalies are greatest in thick clouds, but the overall features are the same for thick and thin clouds. In thin clouds, the warm anomaly occurs below three $\mathrm{km}$ from the cloud top due to their three $\mathrm{km}$ thickness definition.

The cooling anomalies below cloud top occur in both thickness categories, though their magnitudes are different. This indicates that the radiative heating term is not dominant in determining the local temperature anomalies since there is local net radiative heating in thin cirrus clouds (Jensen et al., 1996; Rosenfield et al., 1998), while there is net radiative cooling in thick cloud tops and in cirrus clouds having thick clouds below them (McFarquhar et al., 2000; Hartmann et al., 2001). This radiative heating contributes only to the reduction of the magnitude of the cooling in thin clouds. The sign change from a cooling to a warming anomaly occurs at cloud top. We should note that the cooling anomalies below and warming anomalies above in-situ cirrus might not be a result of cloud-forming processes but a prior condition for cloud formation. We will discuss this further in Sect. 5.

The warming mechanism for the region above the cloud is not clear. There are several hypotheses for this possibility. One of them invokes Kelvin wave generation by convective diabatic cooling in the top levels or convective heating in the free troposphere. The cold anomaly above the warm anomaly in Fig. 3b looks like a wave feature which would support this theory. The other hypothesis involves the direct response to cooling below the cloud top, with a decrease in the local layer thickness and compensating downward motion above the cooling.

We should also be careful about the quantitative analysis of warming anomalies above cloud tops, because our analysis uses local clear sky temperature as the background, and the clear sky temperature is not the same in all domains, due to the longer radiative relaxation time scale versus cloud lifetime, as shown in Fig. 2b. For example, temperature anomalies in clear skies over frequent convective areas still persist after clouds dissipate, although the magnitudes of convective cooling below and warming above the cloud top are reduced with time by radiative relaxation (forcing). Additionally, the difference in the radiative relaxation time with height (the maximum occurs near the cold point) also explains why the maximum cold anomaly from the zonal mean temperature occurs near the cold point (see Fig. 2), even though the maximum occurrence of cloud tops is $1 \sim 2 \mathrm{~km}$ below the cold point (see Fig. 1).

\subsection{Cloud top height vs. water vapor}

Before we investigate the relationship between the cloud top height and environmental water vapor, we examine the relationship between temperature and water vapor using MLS data. Figure 5 shows contours of temperature versus water vapor frequency from MLS at four pressure levels (82, 100,121 , and $146 \mathrm{hPa}$ ), using data obtained from June to $\mathrm{Au}-$ gust 2008 (northern hemisphere summer; NS) and December 2008 to January 2009 (northern hemisphere winter; NW). We selected two different seasons because thermodynamic variables in the TTL have a strong annual cycle (Rosenlof, 1995; Reid and Gage, 1996; Chae and Sherwood, 2007), caused by the Brewer-Dobson circulation, a large scale wave-driven stratospheric circulation (Brewer, 1949; Yulaeva, 1994). The coldest temperature, for example, is shown near $82 \mathrm{hPa}$ in the boreal winter, but near $100 \mathrm{hPa}$ in the boreal summer, and the water vapor mixing ratio in summer is $\sim 2$ ppmv higher than in winter at $100 \mathrm{hPa}$. The dash-dot line indicates the saturated mixing ratio with respect to ice and therefore the overlapping areas, located at the lower right side of the figure, are in supersaturated conditions or overestimated values caused by contamination due to ice particles (clouds). The $82 \mathrm{hPa}$ level in summer, which is in the lower stratosphere above the cold point, is not saturated because there are few clouds present and the relative humidity is low because of the increase in temperature.

MLS data show an interesting relationship between temperature and water vapor (Fig. 5). At $121 \mathrm{hPa}$ and below, the variability of water vapor is relatively large compared to that of temperature, whereas temperature variability is very high at $100 \mathrm{hPa}$ and above. The level between 100 and $121 \mathrm{hPa}$ is a transition layer. Water vapor is negatively correlated with temperature at 146 and $121 \mathrm{hPa}$ (lower TTL). The positive correlation at 100 and $82 \mathrm{hPa}$ (upper TTL) is consistent with the findings of previous studies, in which temperature was found to control water vapor at $100 \mathrm{hPa}$ (Holton and Gettelman, 2001; Read et al., 2004). This demonstrates to us that the physical mechanisms which determine temperature and water vapor at these two levels are different from each other. 


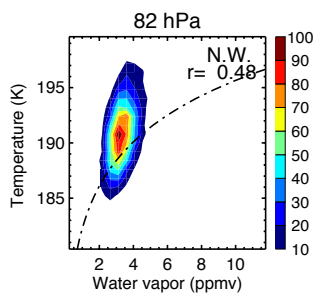

$82 \mathrm{hPa}$

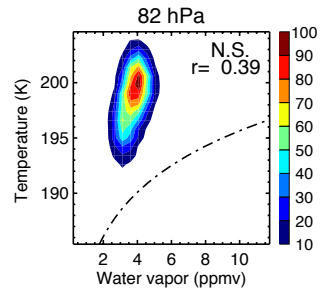

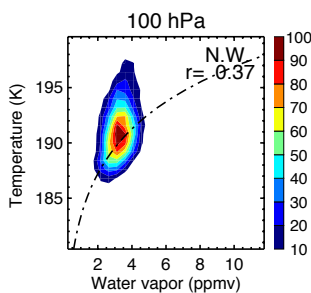

$100 \mathrm{hPa}$

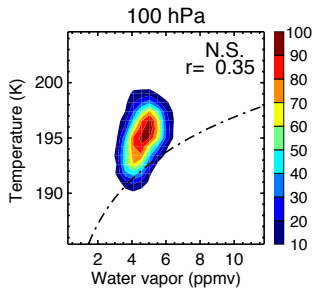

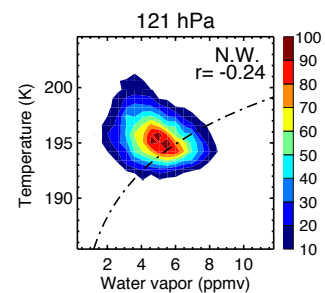

$121 \mathrm{hPa}$

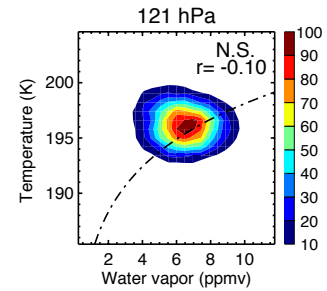

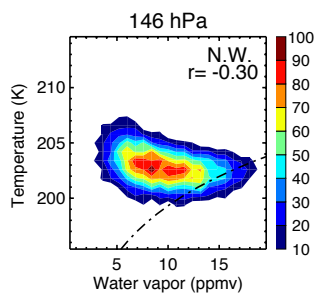

$146 \mathrm{hPa}$

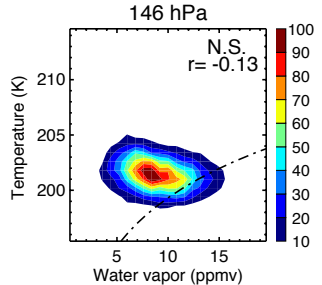

Fig. 5. The contour of temperature versus water vapor frequency from MLS. Dash-dot line shows the saturation line with respect to ice. Upper plots are Northern Hemisphere winter (NW; December 2008 to January 2009), and lower plots Northern Hemisphere summer (NS; June to August 2008).

Table 2. MLS water vapor $(\Delta q)$ and ozone $\left(\Delta \mathrm{O}_{3}\right)$ anomalies above cloud top estimated by an adiabatic vertical displacement based on observed temperature anomalies $\left(\Delta \theta_{\text {obs }}\right)$ at $15.6 \mathrm{~km}$. Actual water vapor $\left(\Delta q_{\text {obs }}\right)$ and ozone $\left(\Delta \mathrm{O}_{3 \mathrm{obs}}\right)$ anomalies are also shown.

\begin{tabular}{cccccccc}
\hline$\Delta \theta_{\text {obs }}$ & $d \theta / d z$ & $d q / d z$ & $\Delta q$ & $\Delta q_{\text {obs }}$ & $\Delta \mathrm{O}_{3} / d z$ & $\Delta \mathrm{O}_{3}$ & $\Delta \mathrm{O}_{3 \mathrm{obs}}$ \\
\hline $1.494 \mathrm{~K}$ & $13.487 \mathrm{~K} / \mathrm{km}$ & $-1.487 \mathrm{ppmv} / \mathrm{km}$ & $-0.165 \mathrm{ppmv}$ & $-0.596 \mathrm{ppmv}$ & $17.347 \mathrm{ppbv} / \mathrm{km}$ & $1.922 \mathrm{ppbv}$ & $3.400 \mathrm{ppbv}$ \\
\hline
\end{tabular}

Water vapor is analyzed in a way similar to temperature in Fig. 3 (Fig. 6). Figure 6a shows the cloudy sky water vapor anomalies from local clear sky water vapor, which increases below $16 \mathrm{~km}$ in cloudy skies but decreases near the cold point. As shown in the temperature analysis, the altitude from 14 to $18 \mathrm{~km}$ can be either above or below the cloud top height. Therefore, we must be careful about inferring possible cloud effects on water vapor in the TTL. Water vapor anomalies above (Fig. 6b) and below the cloud top height (Fig. 6c) are also shown in the same way as the temperature anomalies in Fig. 3.

In the environment below the cloud top, water vapor can either increase or decrease, depending on the height (Fig. 6c). Generally clouds themselves humidify the environment near $16 \mathrm{~km}$ or lower, but dehydrate above $16 \mathrm{~km}$. This can be explained by examining the relative humidity with respect to ice, as shown in Fig. 7. The temperature of the mixed air is always cooled, as shown in Fig. 3c, and the relative humidity increases with height below the cloud tops in the TTL. The air is still sub-saturated with respect to ice below $16 \mathrm{~km}$ (or slightly supersaturated near $16 \mathrm{~km}$ ), and therefore clouds can supply water vapor to the environment at those heights. The environment becomes supersaturated above $16 \mathrm{~km}$, however, and therefore clouds cannot supply water vapor to the environment at those heights. On the contrary, background water vapor due to a temperature drop is deposited onto cloud ice crystals.
On the other hand, water vapor variations above the cloud top are totally different from those below cloud top. Water vapor has negative anomalies above the cloud top if the cloud has penetrated to approximately $14 \mathrm{~km}$ (near the LNB). The magnitude of decreasing water vapor does not depend on cloud top height, but rather on the reference altitude. The bigger decrease of water vapor is at the lower altitudes in the TTL. Water vapor above cloud tops from 17 to $19 \mathrm{~km}$ has positive anomalies as shown in Fig. 2b. It can be explained by downward motion above cloud tops described in the discussion (Sect. 5). Since water vapor has the minimum near $18 \mathrm{~km}$, and increases above this minimum level due to methane oxidation (Fueglistaler et al., 2009), downward motion causes water vapor to increase at this minimum level.

\subsection{Cloud top height vs. ozone}

Ozone can be effectively used as a tracer to understand the physics of the TTL, including for making estimates of cloud top heights and understanding troposphere-stratosphere exchanges (e.g., Folkins et al., 1999). Ozone is vertically well mixed and does not show significant vertical gradients in the troposphere, except that it has a local minimum near $200 \mathrm{hPa}$ in the tropics which is considered to be a level of convective detrainment (see Fueglistaler et al., 2009). However, ozone begins to increase within a transition zone between 14 and $17 \mathrm{~km}$, where the atmospheric chemistry characteristics of the stratosphere begin to develop. 

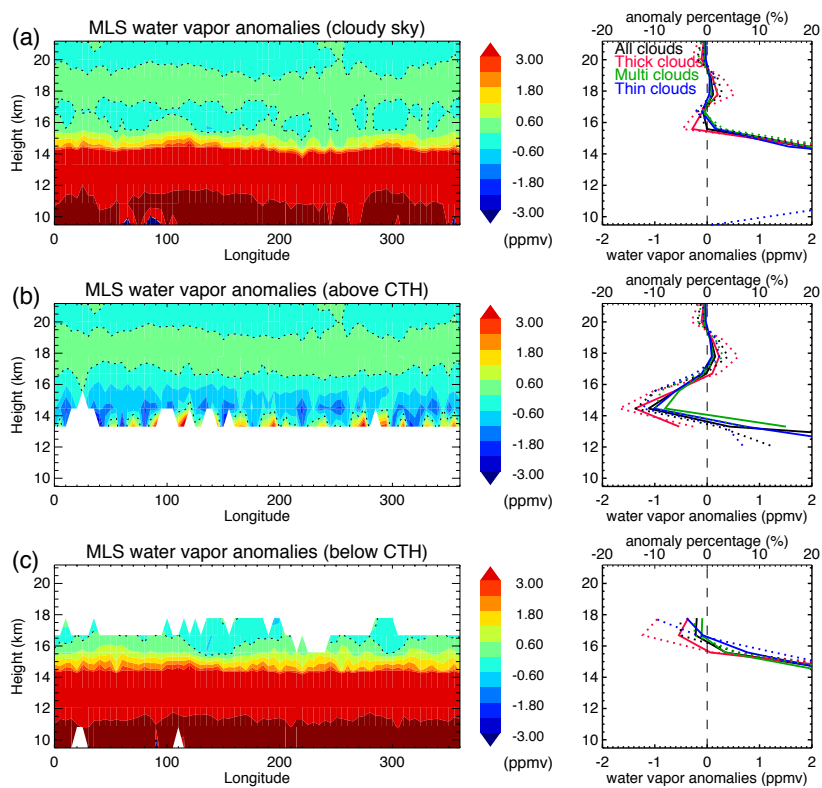

Fig. 6. The same as Fig. 4 except water vapor anomalies. Dot-lines in right figures indicate relative change in percentage with height.

Figure 8 shows ozone anomalies from local clear sky ozone concentrations, determined by the same method of analysis as that used for Figs. 3 and 6. Cloudy sky ozone increases above $16 \mathrm{~km}$ and below $12 \mathrm{~km}$, but decreases between these two levels (Fig. 8a). When we consider the variations of ozone concentrations above and below cloud top height, similar to temperature and water vapor, it is clear that ozone increases above the cloud top but decreases below the cloud top if the reference height is above $12 \mathrm{~km}$ (Fig. $8 \mathrm{~b}$ and c). The increasing ozone anomalies below $12 \mathrm{~km}$ are not a surprising result. Convective upwelling and mixing occur below the cloud top, and the local minimum of ozone is around $12 \mathrm{~km}(200 \mathrm{hPa})$. Therefore, convective upwelling induces an increase below $12 \mathrm{~km}$ but a decrease above that level.

An interesting feature is the increase of ozone above cloud top height. If we assume that chemical ozone production and sinking are both the same in cloudy and clear skies, the ozone increase should be the result of adiabatic processing. It is consistent with that the air above cloud top has a downward motion because ozone concentrations increase with height in the TTL. This agrees well with temperature variations (warm anomalies) and water vapor variations (negative anomalies up to the cold point where water vapor has a local minimum).

We performed a simple estimate of anomalies (cloudy minus clear) of water vapor and ozone due to a vertical displacement, giving the observed change in temperature. If air moves adiabatically, we can estimate the water vapor and ozone anomalies by following equation.

$\Delta A \approx\left(\Delta \theta / \frac{d \theta}{d z}\right) \frac{d A}{d z}$
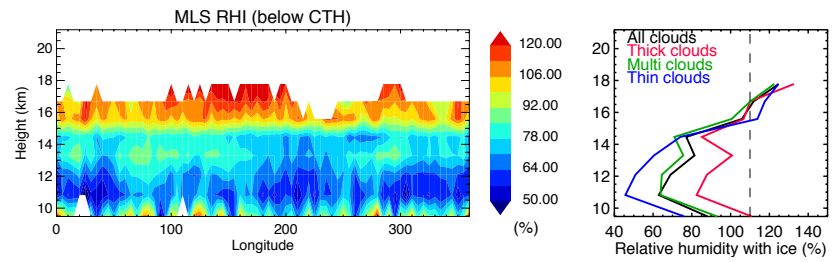

Fig. 7. Relative humidity with respect to ice below cloud top from MLS.
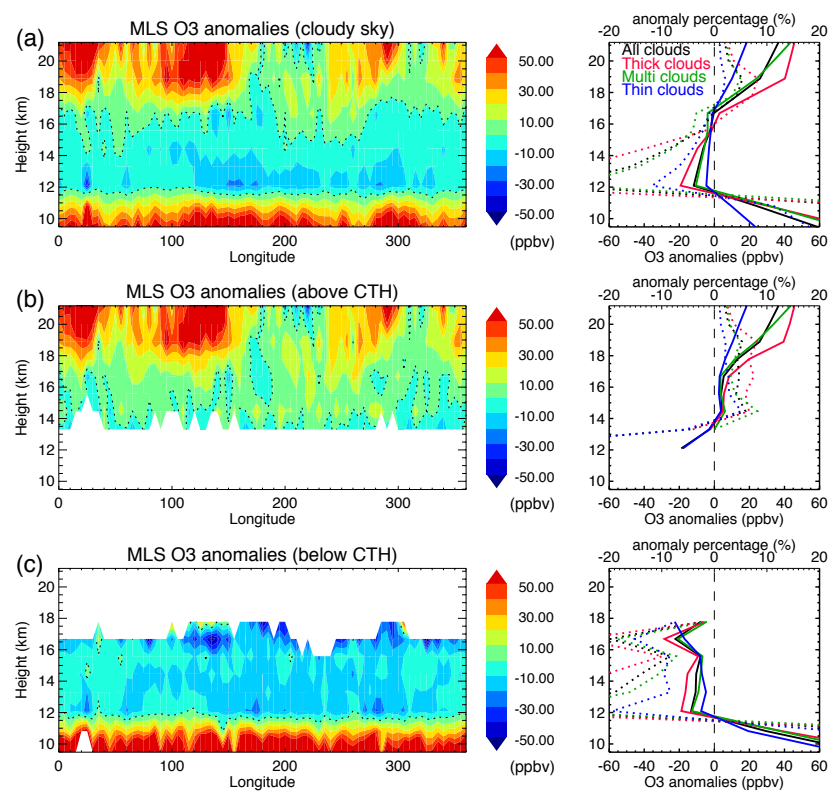

Fig. 8. The same as Fig. 4 except ozone anomalies.

Here, $\theta$ is potential temperature, and $A$ is either water vapor $(q)$ or ozone $\left(\mathrm{O}_{3}\right)$. We used a nine-month average for the observed variables. Table 2 shows an example at $15.6 \mathrm{~km}$. The variation of all three variables, having the same sign as each gradient variation, suggests air descent. Additionally, the observed water vapor and ozone anomalies are two or three times larger than expectations based on temperature. This means that the temperature change is reduced by mixing and cooling during sinking.

\section{Conclusions and discussion}

In this study, we investigated temperature and water vapor variations due to clouds in the TTL using co-located MLS, CALIPSO, and CloudSat datasets. The new lidar measurement of cloud top heights and corresponding environmental variables from A-train satellites in the same orbit enable us to compare variables between each cloud and clear event in the TTL. Tropical deep convection and thin cirrus clouds (above $10 \mathrm{~km}$ ), as seen by CALIPSO, are $2 \sim 4 \mathrm{~km}$ higher than those observed from other instruments. The peak in cloud top 


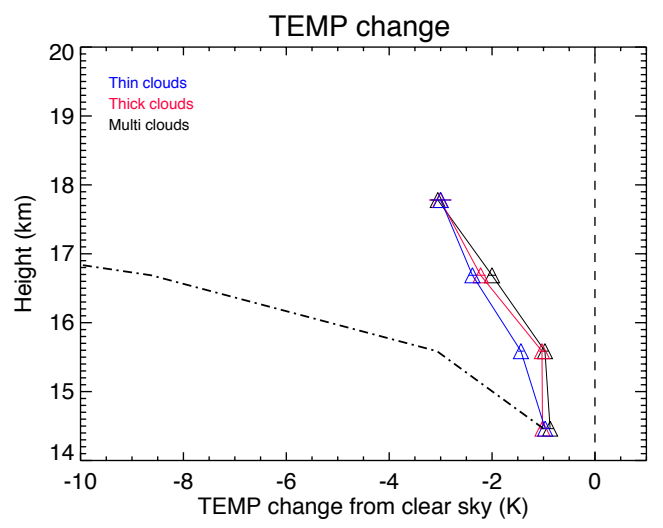

Fig. 9. Temperature anomalies near cloud top from zonal mean clear sky temperature. Dash-dot line shows idealized temperature anomalies without mixing with the environment when we assume that the LNB is $14.5 \mathrm{~km}$.

height frequency of CALIPSO is near $15 \mathrm{~km}$, which is generally above the LNB, and indicates that tropical deep convective clouds and detrained anvil and cirrus clouds often overshoot.

The relationship between clouds and environmental temperature in the TTL clearly shows that cooling occurs only up to cloud top heights, with warming above these heights. These temperature anomalies do not depend on longitude. Thicker clouds are associated with a greater magnitude of temperature anomalies. The magnitude of temperature anomalies may also depend on cloud top height in the TTL for overshooting clouds, because the temperature of an overshooting cloud gets colder with height to a greater extent than the environment (Fig. 9). However, we do not investigate temperature anomalies quantitatively in this study because a long radiative relaxation time induces a memory effect in which the clear-sky temperature is influenced by previous cloud activity. This reduces the temperature anomalies near the cold point over areas of frequent convective activity such as the western Pacific.

Cooling anomalies below the cloud top exist in clouds of all thicknesses, including isolated thin cirrus clouds, which include local radiative heating. Radiative cooling by water vapor can also contribute to a temperature drop, at least up to $16 \mathrm{~km}$, because clouds humidify the environment, but it should be the opposite above $16 \mathrm{~km}$ because clouds dehydrate at these levels. However, we could not find any heating effect below cloud tops when they were above $16 \mathrm{~km}$. Therefore, radiative cooling by water vapor cannot be a dominant cooling factor. Kelvin waves generated by convective heating in the free troposphere can be also considered as one of the cooling factors, but this cannot fully explain why cooling is limited to below cloud tops. This indicates that other cooling factors exist. Another hypothesis for the convective cooling effect is based on turbulent mixing between cold cloudy air and warm environmental air, because overshooting clouds that penetrate the LNB in the TTL are always colder than the environment (see Fig. 9).

The warming anomalies above cloud tops provide interesting results. These warming anomalies occur above all cloud thicknesses, but the magnitude of warming seems to be proportional to the cooling anomalies below cloud top heights, which means that there is more warming and cooling in thick clouds than thin clouds above and below cloud tops, respectively. According to the Eq. (4.1), as well as corresponding water vapor (Fig. 6b) and ozone (Fig. 8b) anomalies, these warming anomalies are due to downward motion. This is inconsistent with previous studies, which investigated the downward motion in the lower stratosphere but ascertained cooling above deep convective cloud tops over the western Pacific (Sherwood, 2000; Fueglistaler et al., 2004). Sherwood and Dessler (2001) used mixing and rearrangement between colder overshooting convective clouds and the warmer environment to explain both downward motion and cooling anomalies. However, the region above cloud tops in previous studies is actually below CALIPSO cloud top heights. Cloud top heights from less sensitive instruments are much lower $(3 \sim 4 \mathrm{~km})$ than lidar cloud top heights (e.g. Weisz et al., 2007). Downward motion and cooling do not occur at the same altitude, and therefore cannot be explained by the same mechanism. There are warm anomalies instead of cool anomalies above cloud tops where air sinks. Cooling is constrained below cloud tops and warm anomalies do not indicate mixing between clouds and environmental air, but rather the response of mixing between sinking air and pre-existing air.

The mechanism of warming and downward motion can be explained by several different hypotheses. The one possible theory is related to the direct response of cooling by clouds. The strongly divergent flow in the cloud layer would, with any turbulent mixing at cloud top, mechanically drag the air just above the cloud outward. By continuity this would suck air down from above over the cloud, giving the subsidence, with compensating ascent occurring just outside the outflow. Additionally the diabatic cooling near cloud top shrinks cloud thickness, and a separate downward motion of air is required above this cooling level. On the opposite side, we can infer that the downward motion and warming are part of a Kelvin wave, and this wave feature affects cloud top heights. Several previous studies have shown that some isolated thin cirrus clouds are generated by Kelvin wave activity (Boehm and Verlinde, 2000; Immler et al., 2008). However, there is no evidence that stratospheric features, including Kelvin waves, can affect the cloud top height of deep convective clouds, and therefore the Kelvin wave itself cannot fully explain temperature anomalies above and below cloud tops.

Water vapor variations in the TTL due to clouds can also be divided into regions above and below cloud tops, with different behavior between the two regions such as temperature. For water vapor variations below cloud tops, it is especially 


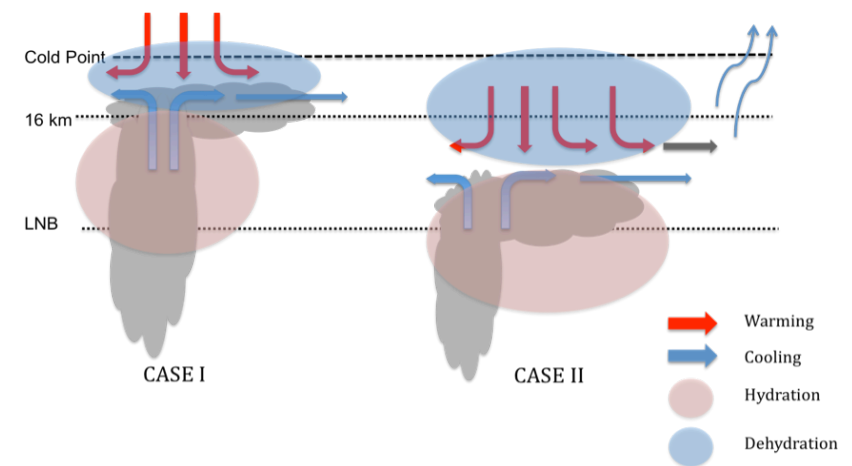

Fig. 10. A schematic of the dehydration and hydration process (including temperature variations) and water vapor transport to the stratosphere above cloud top in the TTL.

important to consider if the cloud top is above or below $16 \mathrm{~km}$. Figure 10 shows a schematic of the dehydration and hydration processing in the TTL. Environmental water vapor below cloud tops can either increase or decrease. The critical factor which divides these different water vapor variations below cloud tops is relative humidity. Clouds hydrate the environment below $16 \mathrm{~km}$, where the relative humidity after mixing between cloud and environmental air does not reach saturation (case II in Fig. 10), but clouds dehydrate above $16 \mathrm{~km}$ because air there is supersaturated due to the bigger temperature drop and the high initial relative humidity (case I in Fig. 10).

Water vapor variations combined with temperature changes above cloud tops suggest "apparent" dehydration mechanism. We used "apparent" here since it reduces humidity in the TTL but must transport water into the stratosphere at the same time. Tropical convection penetrating the LNB cools the environment below cloud top but warms the environment above cloud top and causes air to descend (cases I and II in Fig. 10). The descending air parcels contain less water vapor than the environment. If they mix with the ambient air, they dehydrate these levels, and eventually the mixed dry air parcels are horizontally advected from the convective areas and enter the stratosphere by the Brewer-Dobson circulation.

We do not distinguish between convectively generated and in-situ cirrus clouds. In this paper, we explain cooling and reduced water vapor below cloud top by convectively generated cirrus. However, several studies have argued that cirrus clouds can be formed in situ by Kelvin wave propagation (Boehm and Verlinde, 2000; Randel and Wu, 2005; Virts et al, 2010). Equatorial Kelvin wave ascent can cool air adiabatically, and very thin clouds can be generated below the frost temperature (Jensen et al., 1996). Notwithstanding its different genesis, the same temperature and water vapor anomalies (both negative) might occur incidentally below in-situ cloud tops. Cooling temperatures are not a result of mixing between environmental and cloudy air, but instead a pre-existing condition for in-situ cirrus induced by Kelvin waves. The observation of warming anomalies above in-situ cirrus tops also can be explained by the warm phase of Kelvin waves located above the cold phase.

In this study, because of the limitation of satellite data, we do not investigate temperature anomalies of pre- and postconvective events, which are important for understanding the impact of Kelvin waves on temperatures in the TTL. Therefore, further studies are required for understanding the factors in greater detail that induce temperature variations near cloud top in the TTL.

Acknowledgements. The research was carried out at Jet Propulsion Laboratory, California Institute of Technology, under a contract with National Aeronautics and Space Administration. We would like to thank T. Kubar for help and advice and M. Schwartz for helpful discussions regarding the MLS instrument. This research was funded by NASA grant 443983-LI-79043. Copyright 2010. All rights reserved.

Edited by: T. Garrett

\section{References}

Arakawa, H.: Analysis of the tropopause and the stratospheric field of temperature of a mature typhoon, Pap. Meteorol. Geophys., 2, $1-5,1950$.

Boehm, M. and Verlinde, J.: Stratospheric influence on upper tropospheric tropical cirrus, Geophys. Res. Lett., 27, 3209-3212, 2000.

Brewer, A. W.: Evidence for a world circulation provided by the measurements of helium and water vapor distribution in the stratosphere, Q. J. Roy. Meteorol. Soc., 75, 351-363, 1949.

Chae, J. H. and Sherwood, S. C.: Annual temperature cycle of the tropical tropopause: A simple model study, J. Geophys. Res., 112, D19111, doi:10.1029/2006JD007956, 2007.

Corti, T., Luo, B. P., de Reus, M., Brunner, D., Cairo, F., Mahoney, M. J., Martucci, G., Matthey, R., Mitev, V., dos Santos, F. H., Schiller, C., Shur, G., Sitnikov, N. M., Spelten, N., Vössing, H. J., Borrmann, S., and Peter, T.: Unprecedented evidence for deep convection hydrating the tropical stratosphere, Geophys. Res. Lett., 35, L10810, doi:10.1029/2008GL033641, 2008.

Dessler, A. E., Hanisco, T. F., and Fueglistaler, S.: Effects of Convective ice lofting on $\mathrm{H}_{2} \mathrm{O}$ and $\mathrm{HDO}$ in the tropical tropopause layer, J. Geophys. Res., 112, D18309, doi:10.1029/2007JD008609, 2007.

Folkins, I., Loewenstein, M., Podolske, J., Oltmans, S. J., and Proffit, M.: A barrier to vertical mixing at $14 \mathrm{~km}$ in the tropics: Evidence from ozonesondes and aircraft measurements, J. Geophys. Res., 104(D18), 22095-22102, 1999.

Forster, P. M. de F., and Shine, K. P.: Stratospheric water vapour changes as a possible contributor to observed stratospheric cooling, Geophys. Res. Lett., 26, 3309-3312, 1999.

Froidevaux, L., Jiang, Y. B., Lambert, A., Livesey, N. J., Read, W. G., Waters, J. W., Fuller, R. A., Marcy, T. P., Popp, P. J., Gao, R. S., Fahey, D. W., Jucks, K. W., Stachnik, R. A., Toon, G. C., Christensen, L. E., Webster, C. R., Bernath, P. F., Boone, C. D., Walker, K. A., Pumphrey, H. C., Harwood, R. S., 
Manney, G. L., Schwartz, M. J., Daffer, W. H., Drouin, B. J., Cofield, R. E., Cuddy, D. T., Jarnot, R. F., Knosp, B. W., Perun, V. S., Snyder, W. V., Stek, P. C., Thurstans, R. P., and Wagner, P. A.: Validation of Aura Microwave Limb Sounder stratospheric ozone measurements, J. Geophys. Res., 113, D15S20, doi:10.1029/2007JD008771, 2008.

Fueglistaler, S., Wernli, H., and Peter, T.: Tropical troposphereto-stratosphere transport inferred from trajectory calculations, J. Geophys. Res., 109, D03108, doi:10.1029/2003JD004069, 2004.

Fueglistaler, S., Bonazzola, M., Haynes, P. H., and Peter, T.: Stratospheric water vapor predicted from the Lagrangian temperature history of air entering the stratosphere in the tropics, J. Geophys. Res., 110, D08107, doi:10.1029/2004JD005516, 2005.

Fueglistaler, S., Dessler, A. E., Dunkerton, T. J., Folkins, I., Fu, Q., and Mote, P. W.: Tropical tropopause layer, Rev. Geophys., 47, RG1004, doi:10.1029/2008RG000267, 2009.

Gettelman, A., and Birner, T.: Insights into Tropical Tropopause Layer processes using global models, J. Geophys. Res., 112, D23104, doi:10.1029/2007JD008945, 2007.

Hartmann, D. L., Holton, J. R., and Fu, Q.: The heat balance of the tropical tropopause, cirrus, and stratospheric dehydration, Geophys. Res. Lett., 28, 1969-1972, 2001.

Holloway, C. E., and Neelin, J. D.: The convective cold top and quasi equilibrium, J. Atmos. Sci., 64, 1467-1487, 2007.

Holton, J. R. and Gettelman, A.: Horizontal transport and the dehydration of the stratosphere, Geophys. Res. Lett., 28, 2799-2802, 2001.

Holz, R. E., Ackerman, S. A., Nagle, F. W., Frey, R., Dutcher, S., Kuehn, R. E., Vaughan, M. A., and Baum, B.: Global Moderate Resolution Imaging Spectroradiometer (MODIS) cloud detection and height evaluation using CALIOP, J. Geophys. Res., 113, D00A19, doi:10.1029/2008JD009837, 2008.

Immler, F., Krüger, K., Fujiwara, M., Verver, G., Rex, M., and Schrems, O.: Correlation between equatorial Kelvin waves and the occurrence of extremely thin ice clouds at the tropical tropopause, Atmos. Chem. Phys., 8, 4019-4026, doi:10.5194/acp-8-4019-2008, 2008.

Jensen, E. J., Toon, O. B., Selkirk, H. B., Spinhirne, J. D., and Schoeberl, M. R.: On the formation and persistence of subvisible cirrus clouds near the tropical tropopause, J. Geophys. Res., 101, 21361-21375, 1996.

Jensen, E. J., Ackerman, S. A., and Smith, J. A.: Can overshooting convection dehydrate the tropical tropopause layer?, J. Geophys. Res., 112, D11209, doi:10.1029/2006JD007943, 2007.

Kuang, Z. and Bretherton, C. S.: Convective influence on the heat budget of the tropical tropopause layer: A cloud-resolving model study, J. Atmos. Sci., 61, 2919-2927, 2004.

Kuang, Z., Toon, G. C., Wennberg, P. O., and Yung, Y. L.: Measured $\mathrm{HDO} / \mathrm{H}_{2} \mathrm{O}$ ratio across the tropical tropopause, Geophys. Res. Lett., 30(7), 1372, doi:10.1029/2003GL017023, 2003.

McFarquhar, G. M., Heymsfield, A. J., Spinhirne, J., and Hart, B.: Thin and subvisual tropopause tropical cirrus: observations and radiative impacts, J. Atmos. Sci., 57, 1841-1853, 2000.

Norton, W. A.: Longwave heating of the tropical lower stratosphere, Geophys. Res. Lett., 28, 3653-3656, 2001.

Randel, W. J. and Wu, F.: Kelvin wave variability near the equatorial tropopause observed in GPS radio occultation measurements, J. Geophys. Res., 110, D03102, doi:10.1029/2004JD005006, 2005.
Randel, W. J., Wu, F., and Rivera Ros, W.: Thermal variability of the tropical tropopause region derived from GPS/MET observations, J. Geophys. Res., 108(D1), 4024, doi:10.1029/2002JD002595, 2003.

Reid, G. C. and Gage, K. S.: The tropical tropopause over the western Pacific: Wave driving, convection, and the annual cycle, J. Geophys. Res., 101, 21233-21241, 1996.

Read, W. G., Wu, D. L., Waters, J. W., and Pumphrey, H. C.: A new $137-56 \mathrm{hPa}$ water vapor product from the UARS Microwave Limb Sounder, J. Geophys. Res., 109, D06111, doi:10.1029/2003JD004366, 2004.

Read, W. G., Lambert, A., Bacmeister, J., Cofield, R. E., Christensen, L. E., Cuddy, D. T., Daffer, W. H., Drouin, B. J., Fetzer, E., Froidevaux, L., Fuller, R., Herman, R., Jarnot, R. F., Jiang, J. H., Jiang, Y. B., Kelly, K., Knosp, B. W., Kovalenko, L. J., Livesey, N. J., Liu, H.-C., Manney, G. L., Pickett, H. M., Pumphrey, H. C., Rosenlof, K. H., Sabounchi, X., Santee, M. L., Schwartz, M. J., Snyder, W. V., Stek, P. C., Su, H., Takacs, L. L., Thurstans, R. P., Vömel, H., Wagner, P. A., Waters, J. W., Webster, C. R., Weinstock, E. M., and Wu, D. L.: Aura Microwave Limb Sounder upper tropospheric and lower stratospheric $\mathrm{H}_{2} \mathrm{O}$ and relative humidity with respect to ice validation, J. Geophys. Res. 112, D24S35, doi:10.1029/2007JD008752, 2007.

Read, W. G., Schwartz, M. J., Lambert, A., Su, H., Livesey, N. J., Daffer, W. H., and Boone, C. D.: The roles of convection, extratropical mixing, and in-situ freeze-drying in the tropical tropopause layer, Atmos. Chem. Phys., 8, 6051-6067, 2008, http://www.atmos-chem-phys.net/8/6051/2008/.

Rosenlof, K. H.: Seasonal cycle of the residual mean meridional circulation in the stratosphere, J. Geophys. Res., 100(D3), 51735191, 1995.

Rosenfield, J. E., Considine, D. B., Schoeberl, M. R., and Browell, E. V.: The impact of subvisible cirrus clouds near the tropical tropopause on stratospheric water vapor, Geophys. Res. Lett., 25, 1883-1886, 1998.

Schwartz, M. J., Lambert, A., Manney, G. L., Read, W. G., Livesey, N. J., Froidevaux, L., Ao, C. O., Bernath, P. F., Boone, C. D., Cofield, R. E., Daffer, W. H., Drouin, B. J., Fetzer, E. J., Fuller, R. A., Jarnot, R. F., Jiang, J. H., Jiang, Y. B., Knosp, B. W., Krüger, K., Li, J. -L. F., Mlynczak, M. G., Pawson, S., Russell III, J. M., Santee, M. L., Snyder, W. V., Stek, P. C., Thurstans, R. P., Tompkins, A. M., Wagner, P. A., Walker, K. A., Waters, J. W., and Wu, D. L.: Validation of the Aura Microwave Limb Sounder temperature and geopotential height measurements, J. Geophys. Res., 113, D15S11, doi:10.1029/2007JD008783, 2008.

Sherwood, S. C.: A stratospheric "drain" over the maritime continent, Geophys. Res. Lett., 27, 677-680, 2000.

Sherwood, S. C. and Dessler, A. E.: A model for transport across the tropical tropopause, J. Atmos. Sci., 58, 765-779, 2001.

Sherwood, S. C., Horinouchi, T., and Zeleznik, H. A.: Convective impact on temperatures observed near the tropical tropopause, J. Atmos. Sci., 60, 1847-1856, 2003.

Sherwood, S. C., Chae, J.-H., Minnis, P., and McGill, M.: Underestimation of deep convective cloud tops by thermal imagery, Geophys. Res. Lett., 31, L11102, doi:10.1029/2004GL019699, 2004.

Smith, C. A., Haigh, J. D., and Toumi, R.: Radiative forcing due to trends in stratospheric water vapour, Geophys. Res. Lett., 28, 179-182, 2001.

Stephens, G. L., Vane, D. G., Boain, R. J., Mace, G. G., Sassen, 
K., Wang, Z., Illingworth, A. J., O’Connor, E. J., Rossow, W. B., Durden, S. L., Miller, S. D., Austin, R. T., Benedetti, A., Mitrescu, C., and The CloudSat Science Team: The CloudSat and the A-Train, B. Am. Meteorol. Soc., 83, 1771-1790, 2002.

Tsuda, T., Ratnam, M. V., May, P. T., Alexander, M. J., Vincent, R. A., and MacKinnon, A.: Characteristics of gravity waves with short vertical wavelengths observed with radiosonde and GPS occultation during DAWEK (Darwin Area Wave Experiment), J. Geophys. Res., 109, D20S03, doi:10.1029/2004JD004946, 2004.

Virts, K. S., Wallace, J. M., Fu, Q., and Ackerman, T. P.: Tropical tropopause transition layer cirrus as represented by CALIPSO lidar observation, J. Atmos. Sci., 67, 3113-3129, 2010.

Webster, P. J. and Stephens, G. L.: Tropical upper-tropospheric extended clouds: Inferences from winter MONEX, J. Atmos. Sci., 37, 1521-1541, 1980.

Weisz, E., Li, J., Menzel, W. P., Heidinger, A. K., Kahn, B. H., and Liu, C.: Comparison of AIRS, MODIS, CloudSat and CALIPSO cloud top height retrievals, Geophys. Res. Lett., 34, L17811, doi:10.1029/2007GL030676, 2007.
Wu, D. L., Ackerman, S. A., Davies, R., Diner, D. J., Garay, M. J., Kahn, B. H., Maddux, B. C., Moroney, C. M., Stephens, G. L., Veefkind, J. P., and Vaughan, M. A.: Vertical distributions and relationships of cloud occurrence frequency as observed by MISR, AIRS, MODIS, OMI, CALIPSO, and CloudSat., Geophys. Res. Lett., 36, L09821, doi:10.1029/2009GL037464, 2009.

Wu, D. L., Chae, J. H., Lambert, A., and Zhang, F. F.: Characteristics of CALIOP attenuated backscatter noise: implication for cloud/aerosol detection, Atmos. Chem. Phys., 11, 2641-2654, doi:10.5194/acp-11-2641-2011, 2011.

Yulaeva, E., Holton, J. R., and Wallace, J. M.: On the cause of the annual cycle in tropical lower-stratospheric temperatures, J. Atmos. Sci., 51(2), 169-174, 1994.

Zhou, X. L. and Holton, J. R.: Intraseasonal variations of tropical cold point temperatures, J. Clim., 15, 1460-1473, 2002. 